\title{
Up-Regulation of Insulin-Like Growth Factor-2 Promotes Cell Proliferation and Migration and is Associated with Bone Metastasis in Non Small Cell Lung Cancer.
}

\section{Shuai Han}

Shanghai Pudong New Area people's hospital

\section{Zhenhua Wang}

Changzheng Hospital

\section{Guangjian Bai}

Shanghai Changzheng Hospital

\section{Zhitao Han}

shanghai pudong new area people's hospital

\section{Yunpeng Bai}

shanghai pudong new area people's hospital

\section{Xin Song}

shanghai pudong new area people's hospital

Jin Zeng

First Affiliated Hospital of Nanchang University

\section{Tielong Liu}

Shanghai Changzheng Hospital

Jian Wang ( $\nabla$ wjwj0328@163.com )

shanghai pudong new area people's hospital

\section{Research Article}

Keywords: IGF2,AKT/NF-KB pathway,Bone metastasis,Non-small cell lung cancer

Posted Date: August 9th, 2021

DOI: https://doi.org/10.21203/rs.3.rs-750861/v1

License: (c) (1) This work is licensed under a Creative Commons Attribution 4.0 International License.

Read Full License 


\section{Abstract}

Background:Non-small cell lung cancer (NSCLC) is a malignant tumor with high morbidity and mortality. About $40 \%$ NSCLC patients develop bone metastasis. The aberrant expression of IGF2 (insulin-like growth factor-2) is known to be linked with many malignancies, but it has not been reported in NSCLC.

Methods and Results:We first used the GEO database for differential gene analysis and showed a correlation between IGF2 and bone metastasis in NSCLC. IGF2 was highly expressed in primary NSCLC and even more highly expressed in bone metastases. Our in vivo experiment also showed that IGF2 promoted lung cancer proliferation and migration. In addition, IGF2 overexpression activated AKT/NF-KB pathway by promoting IGF1R and INSR phosphorylation, and enhanced osteolytic lesions in lung cancer.

Conclusions Up-regulation of insulin-like growth factor-2 can promote the proliferation and migration of non-small cell lung cancer cells, and is related to bone metastasis.

\section{Introduction}

Lung cancer is one of the most frequently diagnosed malignancies and the primary cause of cancerassociated mortality[1]. Non-small cell lung cancer (NSCLC) including adenocarcinoma, large-cell carcinoma along with squamous cell carcinoma accounts for more than $85 \%$ of all lung cancer cases[2]. Bone metastasis occurs in $30-40 \%$ of individuals with metastatic lung cancer, causing pathological fractures, hypercalcemia, severe pain, as well as nerve compression[3]. The mean survival of individuals with lung cancer after diagnosis with bone metastasis is often less than 6 months. Thus, limiting bone metastasis is a crux in the clinical treatment of NSCLC[4].

Insulin-like growth factor 2 (IGF2), a polypeptide growth factor family member, is expressed in most tissues[5].Numerous reports suggest that IGF2 modulates cell growth, differentiation, as well as metabolism. There is a close relationship between IGF2 and the development of cancers[6]. Previous researches have documented that IGF2 is abnormally expressed in various human malignancies, and high expression of IGF2 is usually linked to a poor clinical outcome[7-10]. Nevertheless, the role that IGF2 plays in lung cancer and the subsequent cascade of IGF2 remain unclear.

Herein, we illustrated that IGF2 expression was sequentially increased in non-malignant lung tissues, primary NSCLC, as well as NSCLC bone metastasis. Further examination showed that overexpression or knockdown of IGF2 could markedly promote or reduce proliferation, migration along with infiltration of NSCLC cells. Moreover, regulation of IGF2 had an obvious effect on NSCLC cell-induced osteoclastogenesis. Mechanism study showed that IGF2 might activate the AKT/NFKB cascade by targeting IGFR1 and INSR. These data imply that IGF2 might have an indispensable role in NSCLC bone metastasis.

\section{Materials And Methods}




\subsection{Derivation of GEO data and identification of differentially expressed genes (DEGs)}

Herein, two microarray expression profile datasets GSE10096 and GSE43458 were downloaded from the GEO data resource. The annotation data of all the probe sets was on the basis of the GPL571 [HG-UL33A] Affymetrix Human Genome U133A 2.0 Array. In all, 30 non-malignant lung tissues, 80 lung adenocarcinomas and 9 bone metastases lesion samples were used. Then SangerBox (www.soft.sangerbox.com) was applied according to the instructions to uncover DEGs among lung tissues, adenocarcinomas and NSCLC bone metastatic lesions. The top 30 DEGs are presented in a heatmap.

\subsection{Human specimens}

Overall, 70 non-malignant lung tissues, 117 NSCLC tissues, as well as 37 lung cancer bone metastatic tissues were acquired from patients who underwent surgical resection in our hospital from 2007 to 2019. The tissues obtained during surgery were frozen in liquid nitrogen immediately within 2 hours following surgical excision. None of the participants was inoculated with radiotherapy, or chemotherapy prior to surgery. The approval of this study was granted by the Ethics Committee of Changzheng Hospital of the Second Military Medical University (Shanghai, China). Besides, the participants provided informed consent.

\subsection{Cells and culture}

The A549 and PC9 NSCLC cells were commercially provided by SIBCB of the Chinese Academy of Sciences (Shanghai, China). Cells were inoculated in medium (A549 with in DMEM and PC9 in RPMI1640, Thermo Fisher Scientific,USA) enriched with 10\% FBS (Cat No, GIBCO, USA). RAW 246.7 cell were inoculated in MEM a (Cat No, Thermo Fisher Scientific, USA) enriched with 10\% FBS. The culture condition in the cell incubator was $37^{\circ} \mathrm{C}$ and $5 \% \mathrm{CO}_{2}$.

\subsection{IGF2 overexpression plasmid and siRNA}

Kpnl along with EcoRV (Cat Nos, TransGen Biotech, China) were employed to digest the pcDNA3.1 + plasmid. PCR was used to amplify IGF2 coding sequence, followed by insertion into pcDNA3.1 + through the Quick-Fusion Cloning Kit (Cat No, biotool, USA). The oligonucleotide primers for the PCR included; F: ATG GGA ATC CCA ATG GGG AA; R: TCA CTT CCG ATT GCT GGC CA. DNA sequencing was employed to validate the overexpression (OE) plasmid of IGF2. Two distinct siRNA oligos against IGF2 were supplied by IDT. siRNA-1: CGG CCT GGG AAG TAG GAC TAA; siRNA-2: GTA GGA CTA AGG ACC CGA ACT. RT-PCR along with Western blotting were employed to verify IGF2 expression post transfection. 


\subsection{Cell transfection}

Cells in the log growth phase were used once they reached $5070 \%$ confluence. The DNA Transfection Reagent (Bimake) was used according to the operation manual

\subsection{Immunohistochemistry (IHC)}

Tissues were fixed in $4 \%$ PFA at $4^{\circ} \mathrm{C}$ for 24 hours, and sectioned into 4 -mm slices, followed by embedding in paraffin. Afterwards, $2 \%$ hydrogen peroxide dispersed in methanol was employed to block the endogenous peroxidase activity. Thereafter, the slides were inoculated in citrate buffer ( $\mathrm{pH}$ 6.0) and then heated in a microwave oven for 12 minutes to retrieve the antigen. Subsequently, the slides were inoculated with rabbit anti-human IGF2 antibody (cat. no. ab9574; Abcam, Cambridge, MA, USA; 1:1,000). Thereafter, the samples were inoculated with the goat anti-rabbit secondary antibody (Cat No, Dako, Glostrup, Denmark; 1:2000). Then, DAB staining (Cat No, Dako) was done as described by the manufacturer. Finally, light counterstaining of the samples with hematoxylin was done, followed by mounting. Two experienced pathologists assessed the results and images were acquired.

The intensity of staining was scored as; strongly positive, 3; moderately positive, 2; weakly positive; and negative, 0 . Four categories were used in scoring percentage positivity: $>75 \%, 4 ;>50-75 \%, 3 ;>25-50 \%, 2$; $5-25 \%, 1$, and $<5 \%, 0$. The staining score was determined through the multiplication of intensity of staining score with the positivity percentage, and was graded as high expression (score $\geq 3$ ) or low expression (score $\leq 2$ ).

\subsection{Colony formation assay}

Cells were digested, counted, planted in 6-well plates in triplicate, grown for 14 days, washed with PBS, fixed in $4 \%$ PFA, followed by $0.1 \%$ crystal violet staining (Sigma, St Louis). The number of effective colonies consisting of more than 50 cells was counted.

\subsection{Cell cycle assay}

Five hundred A549 or PC9 cells were inoculated in 6-well plates and inserted with pcDNA3.1+, or OE-IGF2 plasmids via transfection 48 hours. We harvested the cells, followed by fixing them with ice-cold $70 \%$ ethanol. Thereafter, the cells were rinsed in PBS, and rehydrated in PBS enriched with propidium iodide $(0.5 \mathrm{mg} / \mathrm{mL}$ dispersed in PBS with $0.1 \%$ sodium azide) and RNase $A(1 \mathrm{mg} / \mathrm{mL})$ for $30 \mathrm{~min}$ in the dark. Finally the FACSCalibur flow cytometer (Becton-Dickinson, USA) was employed to analyze the samples. Lastly, the FlowJo software (Tree Star, USA) was employed to analyze the data.

\subsection{Transwell migration and invasion assay}


The 8- $\mu \mathrm{m}$ pore size transwell insert without matrigel (3422, Corning, USA) and with matrigel (354480, Corning, USA) were utilized for transwell migration and infiltration assay respectively. Digestion of the cells was done, followed by counting. Overall, $1 \times 10^{5}$ cells in $100 \mu \mathrm{L}$ medium enriched with no FBS were inoculated in the upper inserts and $500 \mu \mathrm{L}$ medium augmented with $10 \%$ FBS was inoculated in the lower inserts as chemoattractant and incubated for 24 hours. After that, we removed the cells in the upper inserts, while the bottom surface-cells were fixed with $4 \%$ PFA, followed staining with $0.1 \%$ crystal violet for 15 minutes. After that, 5 random fields were counted with a microscope at $400 \times$. Lastly, acetic acid elution was performed and the OD values read at $570 \mathrm{~nm}$.

\subsection{Western blot}

The RIPA buffer (KeyGen Biotech, Shanghai, China) enriched with PMSF (KeyGen Biotech), protease inhibitor, as well as phosphatase inhibitor cocktail, was employed to lyse the cells. The Western blotting was conducted as documented previously [20]. 20-40 $\mu$ g protein extract was fractionated on a $10 \%$ SDSPAGE gel and transfer-embedded onto PFDV membranes (GE Healthcare Life Sciences, Germany). Next, $5 \%$ non-fat milk was employed to block the membranes. Afterwards, the membranes were inoculated overnight with the primary antibody at $4^{\circ} \mathrm{C}$. Lastly, the SuperSignal ${ }^{B}$ ECL Kit (Cat No, Pierce, USA). Primary antibodies we used are listed Supplementary Data.

\subsection{Reverse transcription-PCR (RT-qPCR)}

The TRIZOL (Cat No, Invitrogen, USA) was employed to isolate total RNA and utilized to generate fiststrand cDNAs with the Prime Script ${ }^{\mathrm{TM}}$ RT Master Mix (Cat No, Takara, Japan). The SYBR ${ }^{\circledR}$ Premix Ex Taq ${ }^{\text {TM }}$ II (Cat No, Takara, Japan) was employed to quantify the mRNA on the 7900HT Fast qRT-PCR System (Life Technologies Corporation, USA). GAPDH was utilized as the normalization standard. The primers are listed Supplementary Data.

\subsection{Osteoclast differentiation assay}

Raw246.7 cells were inoculated with the conditional medium from A549 transfected with OE-IGF2, shIGF2 and their respective control plasmids for 7 days. Thereafter, cells were fixed with $4 \%$ PFA, followed by TRAP staining with the TRAP Kit (Cat No, Sigma-Aldrich) as described by the manufacturer. The number of TRAP-positive multinucleated cells ( $\geq 3$ nuclei, mature osteoclasts) was counted.

\subsection{ELISA}

ELISA was carried out using IGF2 ELISA kit (Cat No, Abnova, Taipei City, Taiwan) as described by the manufacturer. A microplate reader was employed to document the absorbance at $450 \mathrm{~nm}$. The absorbance at $630 \mathrm{~nm}$ was used as a reference. 


\subsection{Statistical analysis}

Results are given as means \pm SEM unless specified. Two-tailed unpaired t-test was employed to compute significant differences between the mean values of groups. The Kaplan Meier plotter website (http://kmplot.com/) was used for OS (overall survival) and PFS (progression-free survival) analysis in NSCLC patients. The IGF2 probe set was 202409_at (although there were three IGF2 probe sets, the results were similar.) The patients were split on the basis of the median, and the univariate cox regression was performed. $\mathrm{P}<0.05$ signified statistical significance.

\section{Results}

\subsection{IGF2 is upregulated in NSCLC bone metastasis and negatively correlated with clinical prognosis.}

Herein, gene expression patterns from two datasets in lung adenocarcinoma were selected for comparison of gene expression. According to the introduction, the samples were divided into three groups. After that, an overlapping analysis of the differential expression genes (DEGs) between the groups was performed. DEGs were defined as genes with $\mathrm{P}<0.05$ along with the absolute fold change $>$ 1.5. The top 30 DEGs are shown in Fig. 1A. It was found that the expression level of IGF2 in the nonmalignant lung tissue was low but sequentially increased in the NSCLC and NSCLC bone metastasis tissues. Then, we used qRT-PCR to validate the mRNA expression of the top 10 DEGs in our own clinical specimens ( 5 non-malignant lung tissues, 5 primary NSCLC tissues and 5 NSCLC bone metastasis tissues). The mRNA expression level of IGF2 was very consistent with the microarray analysis (Fig. 1B). Besides, western blotting along with IHC analysis were employed to compare the expression of IGF2 in the above-mentioned specimens and revealed a similar change in IGF2 mRNA level (Fig. 1C-D). To assess the relationship of IGF2 expression with survival of individuals with the NSCLC, we explored IGF2 expression contribution to OS, as well as FPS of the patients in a clinical microarray data resource containing 1,648 adenocarcinoma patients. The result revealed that elevated expression of IGF2 predicted a poorer OS in individuals with adenocarcinoma (HR = 1.44, $\mathrm{P}=0.000)(\mathrm{Fig} .1 \mathrm{C}-\mathrm{D})$. Moreover, patients harboring elevated IGF2 expression also exhibited a shorter PFS as in contrast with those with low IGF2 content $(H R=1.35, P=0.000$, (Fig. 1C-D ) )

\subsection{IGF2 overexpression promotes proliferation and colony formation in NSCLC cells, while IGF2 inhibition has an opposite effect.}

To explore further the function of IGF2 in NSCLC, we subsequently up- and down- regulated IGF2 expression in NSCLC cells by transfecting overexpression or shRNA plasmid of IGF2. The suppression and overexpression of IGF2 were validated at mRNA, as well as protein levels. As illustrated in Fig. 2, the 
number of colonies was increased in A549, as well as PC9 cells transfected with OE-IGF2 and decreased in cells transfected with sh-IGF2. Additionally, we also performed cell cycle assessment by flow cytometry and found that IGF2 overexpression increased the fraction of cells in S and G2-M-phase, and IGF2 inhibition produced an opposite effect. These data suggest that IGF2 enhanced cell proliferation of NSCLC cells (Fig. 3).

\subsection{IGF2 increases migration and infiltration of NSCLC cells in vitro.}

The relationship of high IGF2 expression in bone metastasis with poor prognosis of NSCLC patients prompted us to investigate whether manipulation of IGF2 could alter the migration along with the infiltration potential of lung cancer cells. Therefore, we knocked down or overexpressed IGF2 in both A549 and PC9 cells, and found that the migration and infiltration of A549 and PC9 cells were either enhanced or suppressed by IGF2 overexpression or knockdown (Fig. 4).

\subsection{IGF2 overexpression promotes NSCLC cell-induced osteoclast differentiation.}

As a kind of secreted protein, IGF2 could be secreted into the microenvironment of tumor cells. To explore further the role of IGF2 in NSCLC bone metastasis, we selected Raw246.7 cells to test the NSCLC cellinduced osteoclast differentiation after altering IGF2 expression. Conditional media from A549 cells inserted with OE-IGF2, sh-IGF2 and their corresponding Ctrl plasmids were employed as different stimuli during osteoclastogenesis. We evaluated the expression of IGF2 in the conditional media of A549 by ELISA. As shown in Fig. 5E, the IGF2 content in the conditional medium from OE-IGF2 A549 cells was significantly increased, while the conditional medium from sh-IGF2 A549 cells was markedly reduced. The TRAP staining assay indicated that the level of TRAP positive multinucleated osteoclast formation was accelerated in Raw246.7 cells inoculated with the conditional medium from OE-IGF2 A549 cells, while it was decreased in Raw246.7 cells inoculated with the conditional media from sh-IGF2 A549 cells (Fig. 5). We also detected the mRNA levels of markers of osteoclasts including TRAP, nuclear factor of activated T cells, NFATC1 (cytoplasmic 1), and CTSK (cathepsin K), and found that the mRNA content of NFATC1, TRAP as well as CTSK were consistent with the results of the osteoclast differentiation test.

\subsection{IGF2 activates AKT/NFKB signaling in Raw246.7 cells by targeting IGFR1 and INSR}

The AKT/NFKB signaling cascade plays an indispensable role in regulating osteoclast differentiation progression in Raw246.7 cells. Multiple detection assays showed that protein contents of NFATc1, TRAP and CTSK were markedly increased in Raw246.7 cells inoculated with IGF2 (Fig. 6A-B). In addition, IGF2 
addition remarkably increased the expression levels of phosphorylated IGFR1, INSR, AKT and NFKB in a dose-dependent approach. Knowing that IGFR1 and INSR are IGF2 receptors, we next evaluated whether knockdown of IGFR1 or INSR by siRNA could inhibit the AKT/NFKB signaling pathway. The result showed that both phosphorylation of AKT and NFKB and the protein level of NFATC1, TRAP and CTSK were partially suppressed after knockdown of IGFR1 or INSR respectively. The IGF2-induced AKT/NFKB phosphorylation and increase of osteoclast markers were markedly reversed by knockdown of IGFR1 and INSR by at the same time (Fig. 6C-E).

\section{Discussion}

Expression of the imprinted gene IGF2 is usually upregulated numerous human cancers, but the molecular mechanisms remain elusive[11-14]. Our current study firstly addressed the upregulation of IGF2 in NSCLC bone metastasis in contrast with primary tumors, and in addition identified the negative relationship of high expression level of IGF2 and poor prognosis in NSCLC patients. Our data substantiate that IGF2 overexpression significantly enhanced NSCLC cell growth, migration and infiltration, which is consistent with the results in other recent studies $[15,16]$. We also demonstrated that IGF2 triggered the ATK/NF-KB pathway through IGFR1 and INSR, thus enhancing osteoclastogenesis.

IGF2, a $7.5 \mathrm{kDa}$ mitogenic peptide hormone, is secreted by the liver and numerous other organ tissues[5]. IGF2 is upregulated in many cancers and is linked to resistance to chemotherapy and dismal prognosis, [6] as represented by more rapid progression of the disease in chronic myeloid leukemia, shorter time to disease relapse in esophageal cancer and higher mortality in breast cancer, ovarian cancer and colorectal cancer[11, 17-20]. Recent research findings also suggest that IGF2 expression facilitates lung tumorigenesis and indicates poor prognosis in NSCLC[10]. Jang et al demonstrated that psychologic stress activated the IGF-1R pathway by inducing exocytosis of IGF2 in lung epithelial cells and promoted lung tumorigenesis in mice[21]. These results were predictable, cause many studies have shown that as a mitogenic peptide hormone, secretes the function of IGF2 is regulating cell growth, differentiation and metabolism[5, 10, 22].

Bone is one of the most frequent organs of NSCLC metastasis. The occurrence of bone metastasis entails osteolysis and cancer cell growths[15, 23]. To the best of our knowledge, the role of IGF2 in NSCLC bone metastasis remains unclear. Fukuoka et al documented that hypoxic stress promoted differentiation

of osteoclasts through accelerating IGF2 generation by non-osteoclastic cells[24]. Nakao et al pointed out that stimulation of exogenous IGF2 from the initial stage was more pivotal relative to the later stage for the promotion of osteoclastogenesis[25]. Our results indicate that NSCLC cells produced IGF2 in an autocrine or paracrine manner, auutocrine secretion of IGF2 stimulated cancer cell proliferation and migration, and paracrine secretion of IGF2 enhanced osteoclast differentiation of Raw 246.7 cells. Murayama et al reported that IGF2 autocrine and paracrine circuit conferred cancer stem cell-like features in lung cancer[26]. More interestingly, Xu et al demonstrated that IGF2 secreted from cancer cells instigated fibroblasts and bone marrow derived neovascularization and angiogenesis[15] .Given the potential impacts of IGF2 in the bone microenvironment and progress of cancer, we suggest that IGF2 
participates in the onset of bone metastasis and could be a prospective prognostic biomarker and targeting opportunity for NSCLC.

Similarly to IGF1, IGF2 is known as a modulator of G1 to S phase transition[27]. IGF2 promotes cancer cell growth and epithelial-mesenchymal transition (EMT) through mainly IGF1R[28]. IGF1R is a receptor tyrosine kinase and signals downstream to the PI3K/AKT and mTOR pathways[6]. There are other types of IGF2 receptors. Indeed, we found that INSR, a G protein coupled receptor, is also a candidate receptor of IGF2, which mediates the activation of the PI3K/AKT casacde. The classic NF-KB signaling cascade is known to play an indispensable role in osteoclast differentiation[29]. Several studies have shown the interaction of the PI3K/AKT cascade with the NF-KB signaling casacde[8, 16, 30]. The PI3K catalytic subunit PI3K-p110 $a$ along with its modulatory subunit $p 85$ have been documented to directly activate NFKB. The activation of PI3K also phosphorylates AKT with successive activation of the p65RelA subunit of NFKB through phosphorylation at S534 via the IKK complex. Phospho-AKT triggers IKKa to phosphorylate IkB, allowing NFKB to translocate into the nucleus[31]. Our study showed that IGF1R and INSR were both important in IGF2-induced osteoclastic differentiation of RAW264.7 cells.

In summary, herein, we established that IGF2 was upregulated in NSCLC bone metastasis in contrast with that in primary tumors, and acted as a prospective tumor promoter by modulating cell proliferation and infiltration. Furthermore, we identified that IGF2 activated the AKT/NFKB pathway to promote cancer cellinduced osteoclastogenesis by binding IGF1R and INSR. These data illustrate that IGF2 may prove to be a novel promising treatment target for lung cancer bone metastasis.

\section{Declarations}

\section{ACKNOWLEDGMENTS}

Not applicable.

\section{Funding}

The present study was supported by the National Natural Science Foundation of China (grant nos.81972506), the PLA logistics research project (grant nos.BWS14C020), the National Natural Science Foundation of China (grant nos.82003132) and Pudong New Area Health System Key Speciality (grant nos.PWZ2k2017-15).

\section{Availability of data and material}

Not applicable.

\section{Code availability}




\section{Authors' contributions}

Jian Wang, Tielong Liu and Jin Zeng conceived and designed the study; Shuai Han Guangjian Bai and Yunpeng Bai analyzed and interpreted the patient data; Zhitao Han, Zhenhua Wang performed the experiments; Shuai Han and Guangjian Bai wrote the manuscript; Shuai Han Zhenhua Wang and Xin Song performed the statistical analysis and data presentation; Jian Wang, Tielong Liu and Jin Zeng reviewed the manuscript and agreed to be accountable for all aspects of the work; All authors read and approved the manuscript. Shuai Han, Zhenhua Wang and Guangjian Bai contributed equally to this atricle and should be considered co-first authors.

\section{Ethics approval and consent to participate}

The present study was approved by the Ethics Committee of our center and written informed consent was obtained from the surviving patients, or family members of those who had succumbed.

\section{Patient consent for publication}

Not applicable.

\section{Competing interests}

The authors declare that they have no competing interests.

\section{References}

1. Siegel RL, Miller KD, Jemal A (2020) Cancer statistics, 2020. CA Cancer J Clin 70(1):7-30

2. Barnett R (2017) Lung cancer. Lancet 390(10098):928

3. Fornetti J, Welm AL, Stewart SA (2018) Understanding the Bone in Cancer Metastasis. J Bone Miner Res 33(12):2099-2113

4. Miller KD, Nogueira L, Mariotto AB, Rowland JH, Yabroff KR, Alfano CM, Jemal A, Kramer JL, Siegel RL (2019) Cancer treatment and survivorship statistics, 2019. CA Cancer J Clin 69(5):363-385

5. Livingstone C (2013) IGF2 and cancer. Endocr Relat Cancer 20(6):R321-R339

6. Brouwer-Visser J, Huang GS (2015) IGF2 signaling and regulation in cancer. Cytokine Growth Factor Rev 26(3):371-377

7. Kasprzak A, Adamek A. Insulin-Like Growth Factor 2 (IGF2) Signaling in Colorectal Cancer-From Basic Research to Potential Clinical Applications. Int J Mol Sci 2019; 20(19) 
8. Danielsen SA, Eide PW, Nesbakken A, Guren T, Leithe E, Lothe RA (2015) Portrait of the PI3K/AKT pathway in colorectal cancer. Biochim Biophys Acta 1855(1):104-121

9. Gao T, Liu X, He B, Pan Y, Wang S (2020) Long non-coding RNA 91H regulates IGF2 expression by interacting with IGF2BP2 and promotes tumorigenesis in colorectal cancer. Artif Cells Nanomed Biotechnol 48(1):664-671

10. Manabe T, Yasuda H, Terai H (2020) et al. IGF2 Autocrine-Mediated IGF1R Activation Is a Clinically Relevant Mechanism of Osimertinib Resistance in Lung Cancer. Mol Cancer Res 18(4):549-559

11. Dong Y, Li J, Han F, Chen H, Zhao X, Qin Q, Shi R, Liu J (2015) High IGF2 expression is associated with poor clinical outcome in human ovarian cancer. Oncol Rep 34(2):936-942

12. Kalla Singh S, Tan QW, Brito C, De León M, Garberoglio C, De León D. Differential insulin-like growth factor II (IGF-II) expression: A potential role for breast cancer survival disparity. Growth Horm IGF Res 2010; 20(2):162-170

13. Zhao R, DeCoteau JF, Geyer CR, Gao M, Cui H, Casson AG (2009) Loss of imprinting of the insulin-like growth factor II (IGF2) gene in esophageal normal and adenocarcinoma tissues. Carcinogenesis 30(12):2117-2122

14. El Tayebi HM, Salah W, El Sayed IH, Salam EM, Zekri AR, Zayed N, Salem ES, Esmat G, Abdelaziz Al. Expression of insulin-like growth factor-II, matrix metalloproteinases, and their tissue inhibitors as predictive markers in the peripheral blood of HCC patients. Biomarkers 2011 ; 16(4):346-354

15. Xu WW, Li B, Guan XY, Chung SK, Wang Y, Yip YL, Law SY, Chan KT, Lee NP, Chan KW, Xu LY, Li EM, Tsao SW, He QY, Cheung AL (2017) Cancer cell-secreted IGF2 instigates fibroblasts and bone marrow-derived vascular progenitor cells to promote cancer progression. Nat Commun 8:14399

16. Hamamura K, Zhang P, Yokota H (2008) IGF2-driven PI3 kinase and TGFbeta signaling pathways in chondrogenesis. Cell Biol Int 32(10):1238-1246

17. Tominaga K, Shimamura T, Kimura N, Murayama T, Matsubara D, Kanauchi H, Niida A, Shimizu S, Nishioka K, Tsuji El, Yano M, Sugano S, Shimono Y, Ishii H, Saya H, Mori M, Akashi K, Tada KI, Ogawa T, Tojo A, Miyano S, Gotoh N (2017) Addiction to the IGF2-ID1-IGF2 circuit for maintenance of the breast cancer stem-like cells. Oncogene 36(9):1276-1286

18. Xu WW, Li B, Zhao JF, Yang JG, Li JQ, Tsao SW, He QY, Cheung A (2018) IGF2 induces CD133 expression in esophageal cancer cells to promote cancer stemness. Cancer Lett 425:88-100

19. Xie J, Chen X, Zheng J, Li C, Stacy S, Holzenberger M, Hu X, Zhang CC (2015) IGF-IR determines the fates of BCR/ABL leukemia. J Hematol Oncol 8:3

20. Murphy N, Carreras-Torres R, Song M, Chan AT, Martin RM, Papadimitriou N, Dimou N, Tsilidis KK, Banbury B, Bradbury KE, Besevic J, Rinaldi S, Riboli E, Cross AJ, Travis RC, Agnoli C, Albanes D, Berndt SI, Bézieau S, Bishop DT, Brenner H, Buchanan DD, Onland-Moret NC, Burnett-Hartman A, Campbell PT, Casey G, Castellví-Bel S, Chang-Claude J, Chirlaque MD, de la Chapelle A, English D, Figueiredo JC, Gallinger SJ, Giles GG, Gruber SB, Gsur A, Hampe J, Hampel H, Harrison TA, Hoffmeister M, Hsu L, Huang WY, Huyghe JR, Jenkins MA, Keku TO, Kühn T, Kweon SS, Le Marchand L, Li Cl, Li L, Lindblom A, Martín V, Milne RL, Moreno V, Newcomb PA, Offit K, Ogino S, Ose J, Perduca 
V, Phipps Al, Platz EA, Potter JD, Qu C, Rennert G, Sakoda LC, Schafmayer C, Schoen RE, Slattery ML, Tangen CM, Ulrich CM, van Duijnhoven F, Van Guelpen B, Visvanathan K, Vodicka P, Vodickova L, Vymetalkova V, Wang H, White E, Wolk A, Woods MO, Wu AH, Zheng W, Peters U, Gunter MJ. Circulating Levels of Insulin-like Growth Factor 1 and Insulin-like Growth Factor Binding Protein 3 Associate With Risk of Colorectal Cancer Based on Serologic and Mendelian Randomization Analyses. Gastroenterology 2020; 158(5):1300-1312.e20

21. Jang HJ, Boo HJ, Lee HJ, Min HY, Lee HY (2016) Chronic Stress Facilitates Lung Tumorigenesis by Promoting Exocytosis of IGF2 in Lung Epithelial Cells. Cancer Res 76(22):6607-6619

22. Li B, Tsao SW, Chan KW, Ludwig DL, Novosyadlyy R, Li YY, He QY, Cheung AL (2014) Id1-induced IGFII and its autocrine/endocrine promotion of esophageal cancer progression and chemoresistanceimplications for IGF-II and IGF-IR-targeted therapy. Clin Cancer Res 20(10):2651-2662

23. Ferrari L, Bajetta E, Martinetti A, Celio L, Longarini R, La Torre I, Buzzoni R, Gattinoni L, Seregni E, Bombardieri E (2003) Could exemestane affect insulin-like growth factors, interleukin 6 and bone metabolism in postmenopausal advanced breast cancer patients after failure on aminoglutethimide, anastrozole or letrozole. Int J Oncol 22(5):1081-1089

24. Fukuoka H, Aoyama M, Miyazawa K, Asai K, Goto S (2005) Hypoxic stress enhances osteoclast differentiation via increasing IGF2 production by non-osteoclastic cells. Biochem Biophys Res Commun 328(4):885-894

25. Nakao K, Aoyama M, Fukuoka H, Fujita M, Miyazawa K, Asai K, Goto S (2009) IGF2 modulates the microenvironment for osteoclastogenesis. Biochem Biophys Res Commun 378(3):462-466

26. Murayama T, Nakaoku T, Enari M, Nishimura T, Tominaga K, Nakata A, Tojo A, Sugano S, Kohno T, Gotoh N (2016) Oncogenic Fusion Gene CD74-NRG1 Confers Cancer Stem Cell-like Properties in Lung Cancer through a IGF2 Autocrine/Paracrine Circuit. Cancer Res 76(4):974-983

27. Gao S, Lin Z, Li C, Wang Y, Yang L, Zou B, Chen J, Li J, Feng D, Song Z, Liu G (2019) IncINS-IGF2 Promotes Cell Proliferation and Migration by Promoting G1/S Transition in Lung Cancer. Technol Cancer Res Treat 18:1533033818823029

28. Vaquero J, Lobe C, Tahraoui S, Clapéron A, Mergey M, Merabtene F, Wendum D, Coulouarn C, Housset C, Desbois-Mouthon C, Praz F, Fouassier L (2018) The IGF2/IR/IGF1R Pathway in Tumor Cells and Myofibroblasts Mediates Resistance to EGFR Inhibition in Cholangiocarcinoma. Clin Cancer Res 24(17):4282-4296

29. Bellavia D, Salamanna F, Raimondi L, De Luca A, Carina V, Costa V, Alessandro R, Fini M, Giavaresi G. Deregulated miRNAs in osteoporosis: effects in bone metastasis. Cell Mol Life Sci 2019; 76(19):3723-3744

30. Lee KB, Byun HJ, Park SH, Park CY, Lee SH, Rho SB (2012) CYR61 controls p53 and NF-KB expression through PI3K/Akt/mTOR pathways in carboplatin-induced ovarian cancer cells. Cancer Lett 315(1):86-95

31. Ghoneum A, Said N. PI3K-AKT-mTOR and NFKB Pathways in Ovarian Cancer: Implications for Targeted Therapeutics. Cancers (Basel) 2019; 11(7) 
A

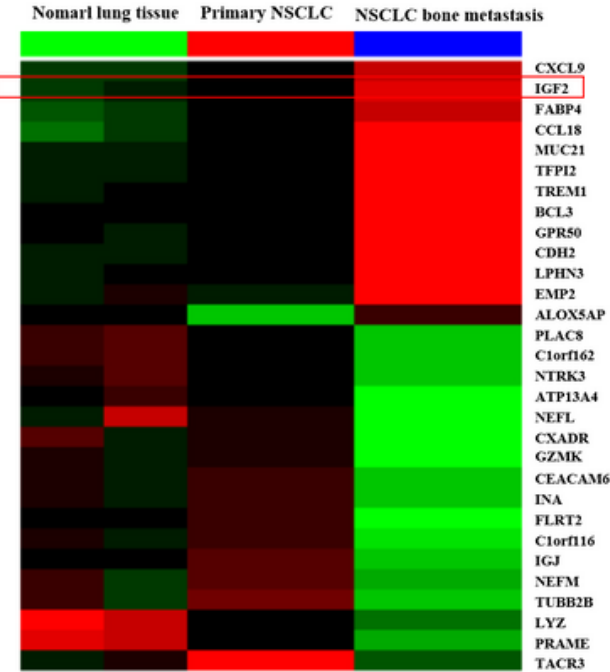

C

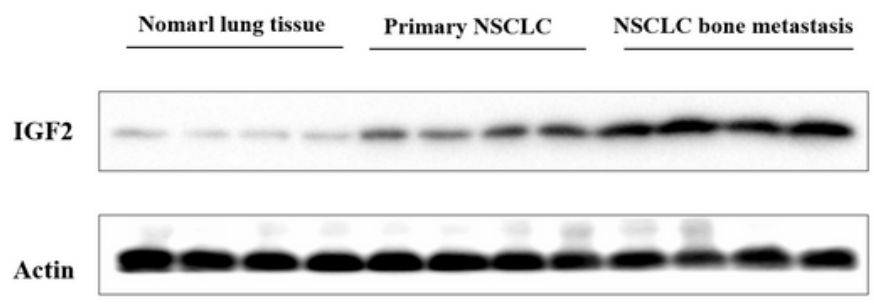

D

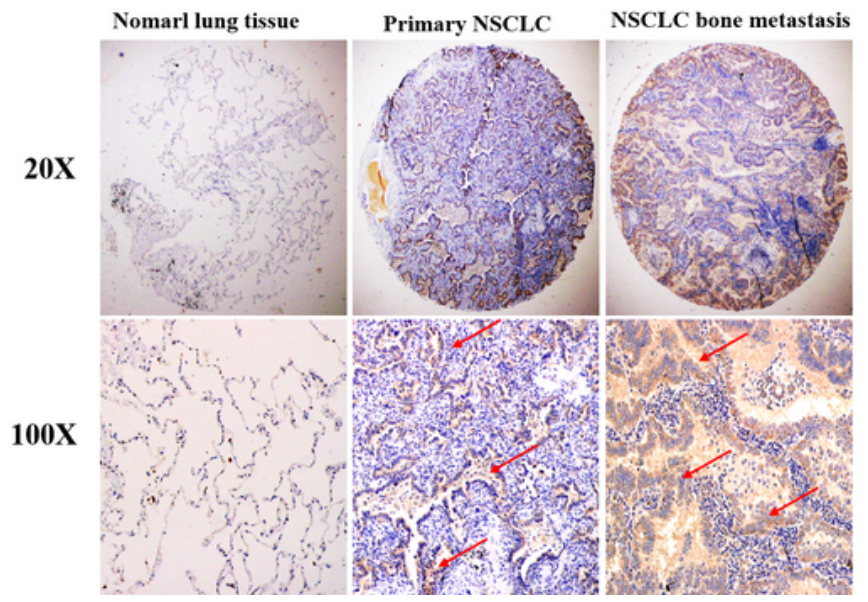

B

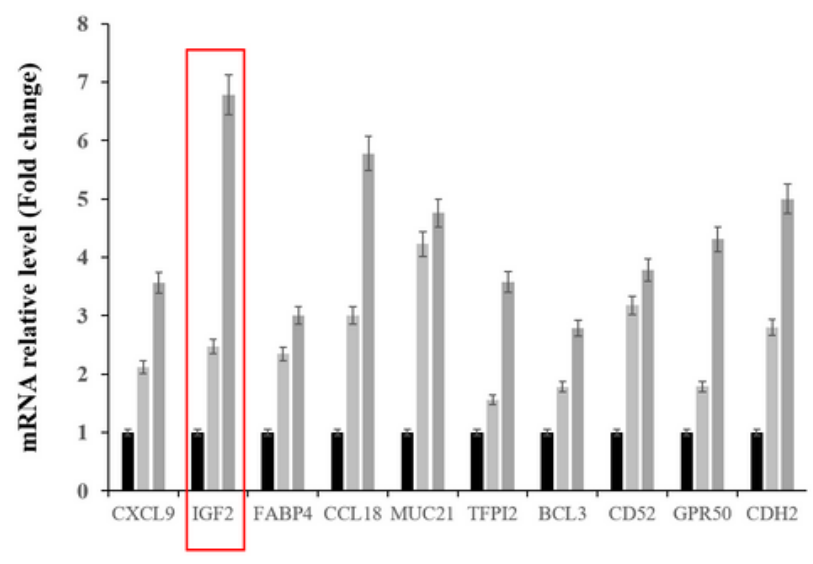

E

FLJ44734 (202410_x_at)

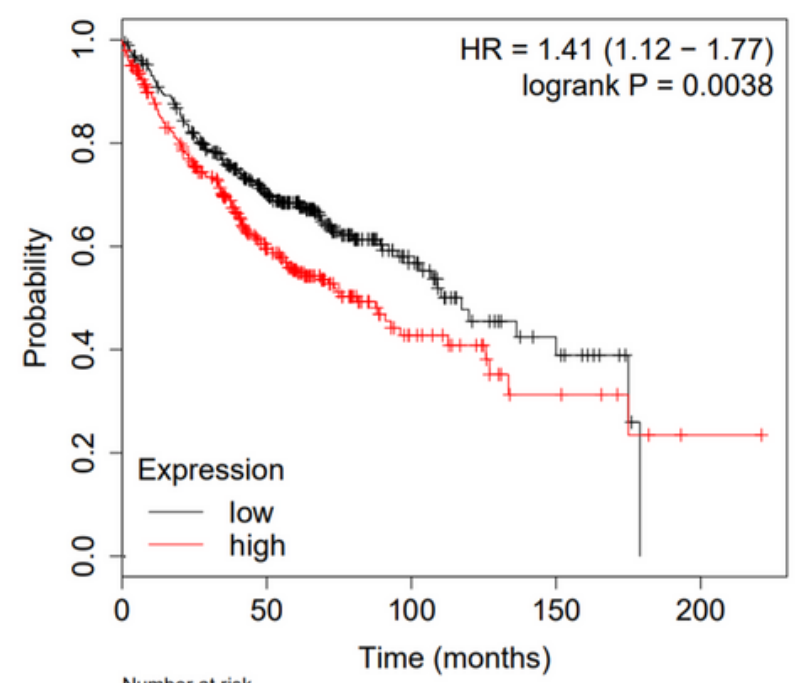

\begin{tabular}{rrrrr}
\multicolumn{5}{c}{ Number at risk } \\
low 378 & 210 & 42 & 12 & 0 \\
high 341 & 137 & 27 & 7 & 1
\end{tabular}

\section{Figure 1}

IGF2 is highly expressed in NSCLC bone metastasis. (A) Heatmap of differential genes among nonmalignant lung tissue, primary NSCLC, as well as NSCLC bone metastasis. (B) Verification of the top 10 differential genes mRNA expression in clinical samples by using quantitative RT-PCR analysis. (C,D) 
Immunohistochemistry and immunoblot analysis of IGF2 protein expression in clinical samples. (E) Kaplan-Meier survival assessment of IGF2 expression in 719 participants in the patients with NSCLC. The analysis split patients by median of the IGF2 expression level. The expression range of the probe was 202410_x_at. Each bar designates mean \pm s.d. of triplicate experiments. ${ }^{*} P<0.05$, Student's t-test. $* *: p<$ 0.01 (Student's t-test).

A

A549 Cell

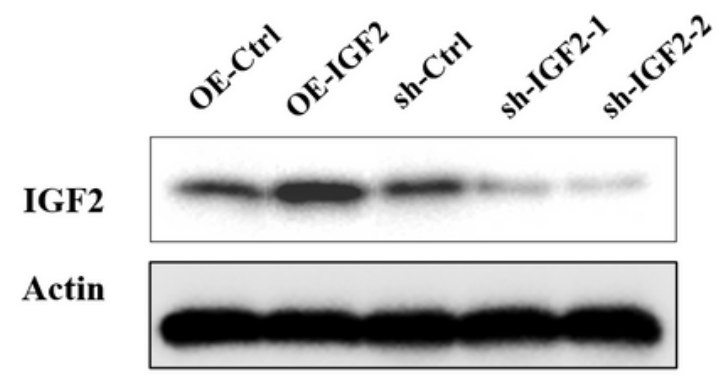

$\mathrm{B}$

A549 Cell

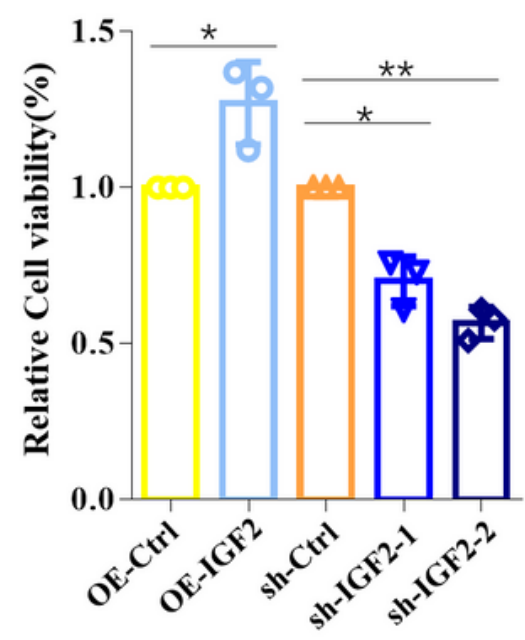

$\mathrm{C}$

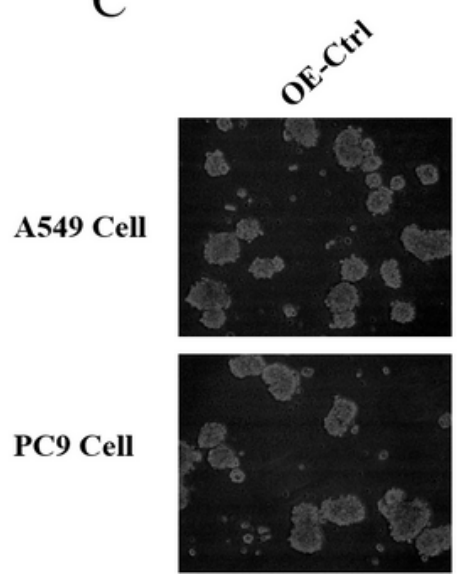

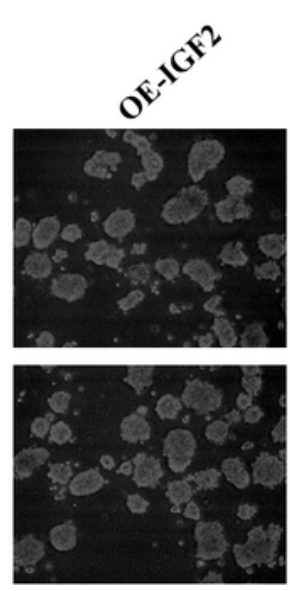
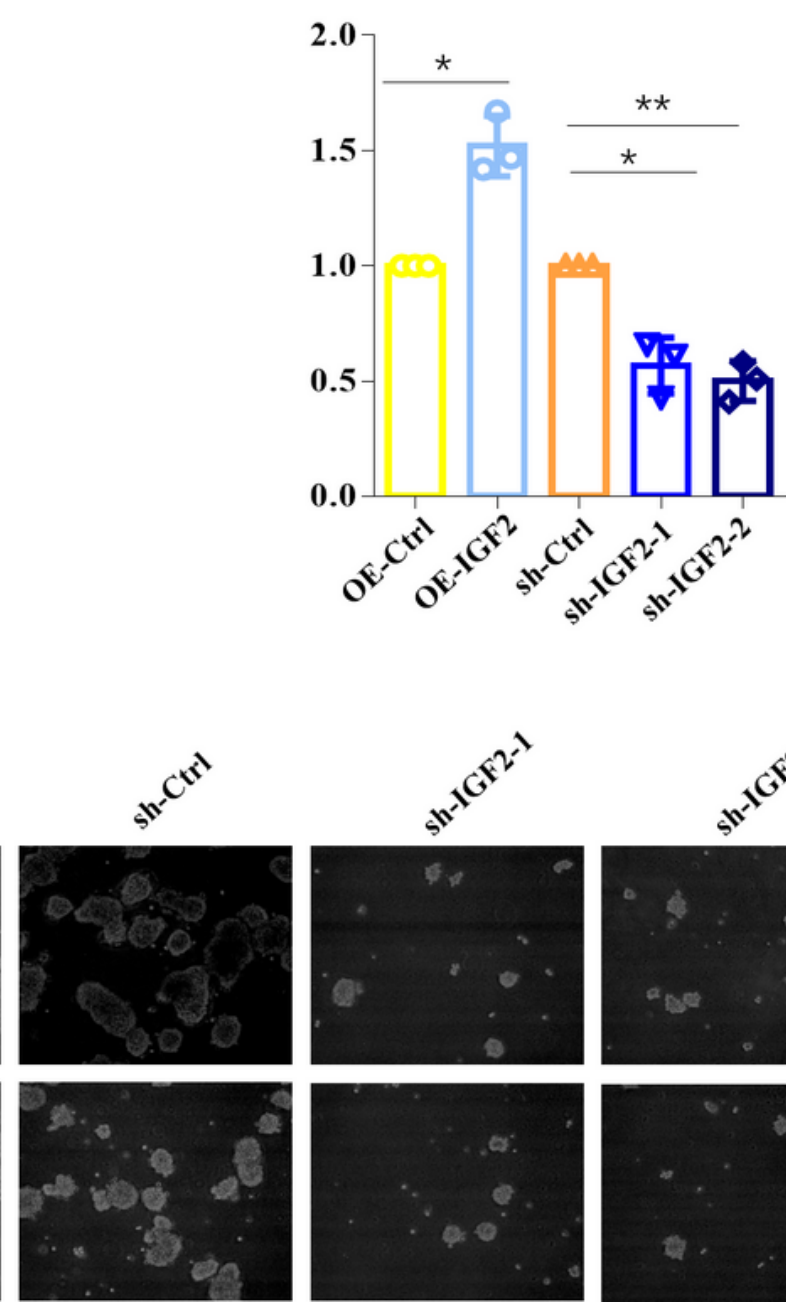

Figure 2 
IGF2 enhances NSCLC cell growth. (A) A549 and PC9 cell were inserted with pcDNA3.1-HA-IGF2 or siRNA via transfection. (B) CCK8 analysis of the growth of A549 and PC9 cells after IGF2 expression alteration (C) Photomicrograph showing colony formation changes in A549, as well as PC9 cells after alteration in IGF2 expression. Each bar designates mean \pm s.d. of triplicate experiments. ${ }^{*} \mathrm{P}<0.05$, Student's t-test. $* *: p<$ 0.01 (Student's t-test).

A

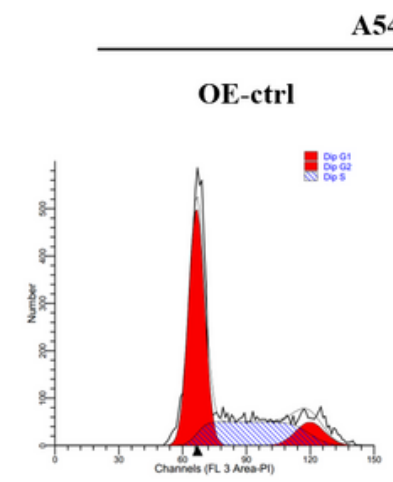

A549 Cell
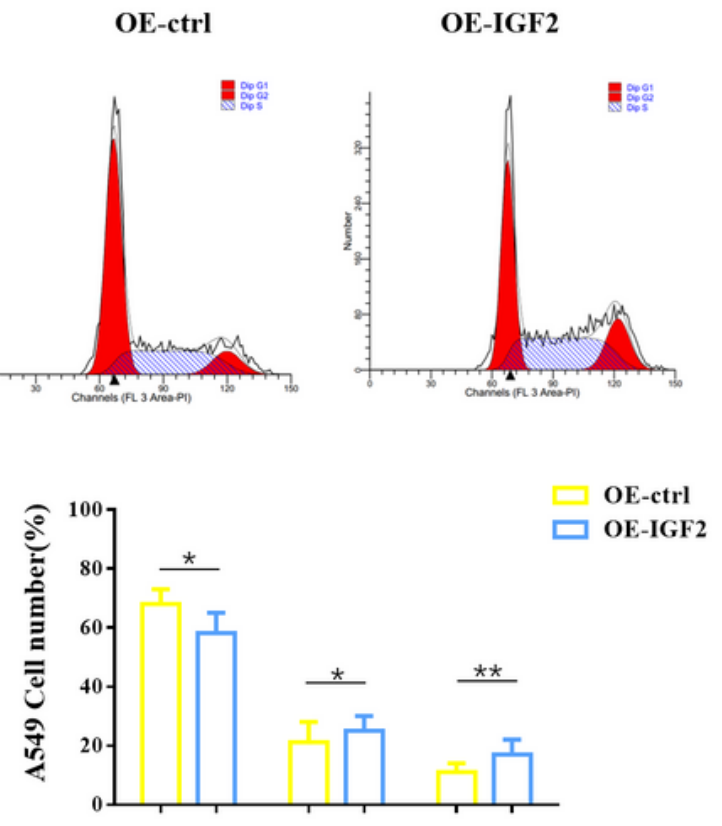

$\mathrm{B}$

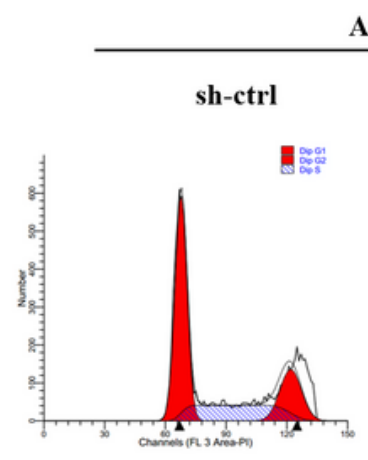

A549 Cell
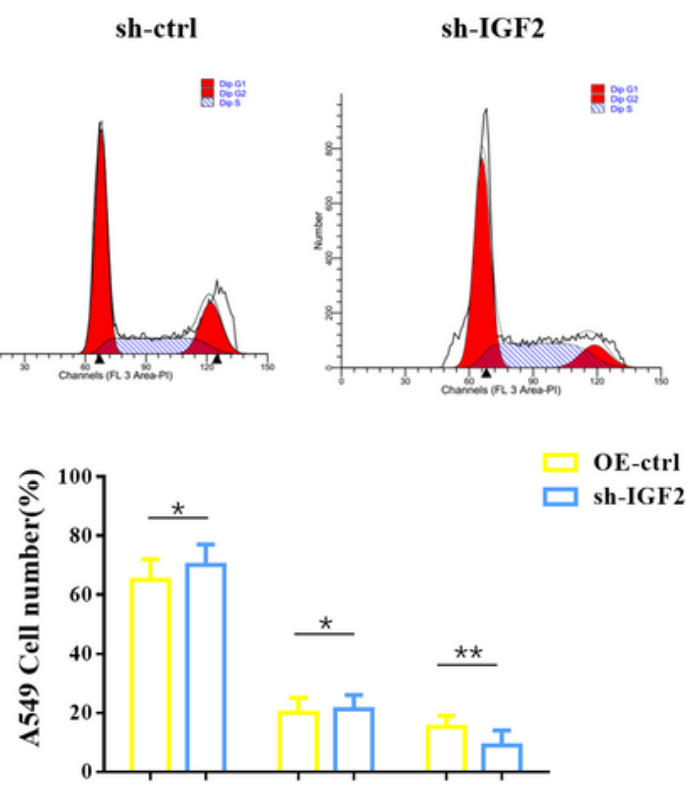
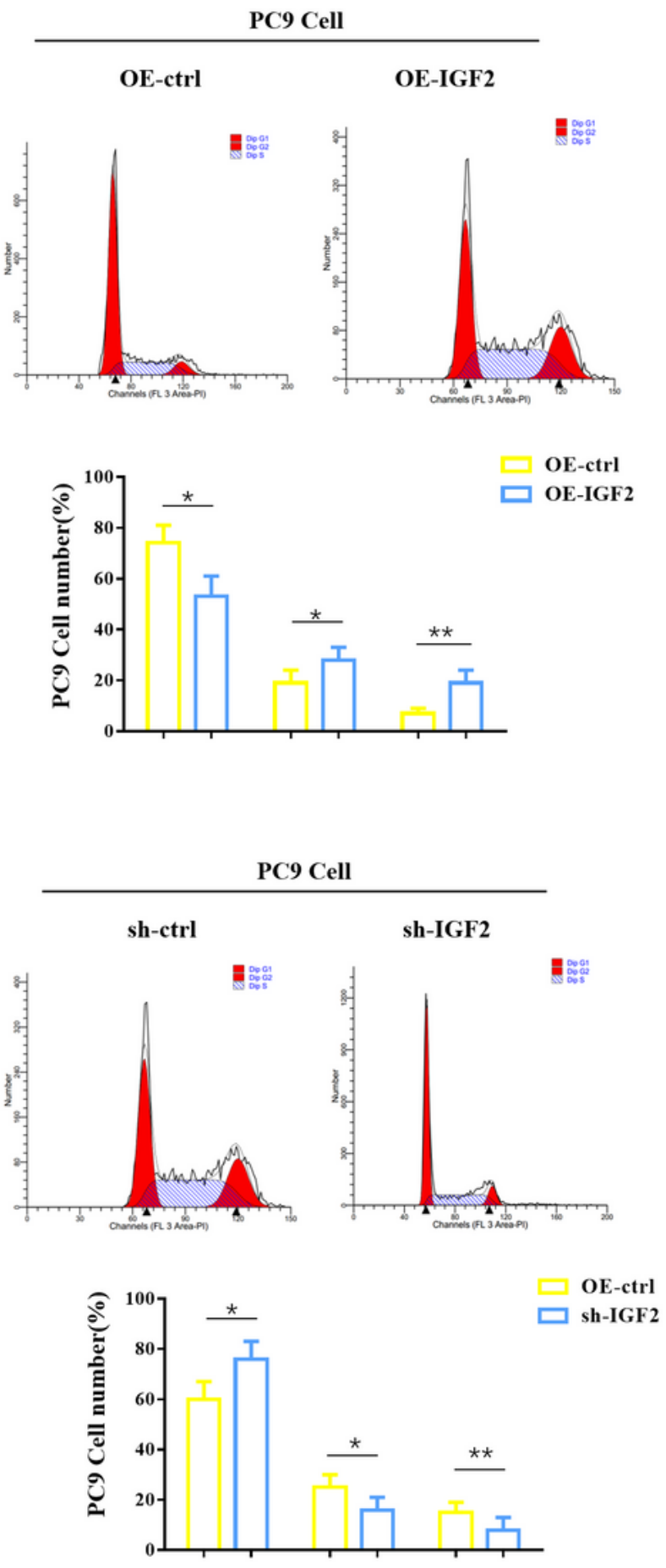

Figure 3 
IGF2 knockdown induces cell cycle change in c NSCLC cells. (a) Cell cycle profile of A549, as well as PC9 cells transfection with OE- IGF2 or OE-CTRL plasmids as determined by flow cytometry. (b) Cell cycle profile of A549 and PC9 cell transfects of sh- IGF2 or sh-CTRL plasmids as determined by flow cytometry. Each bar designates mean \pm s.d. of triplicate experiments. ${ }^{*} P<0.05$, Student's t-test. ${ }^{* *}: p<0.01$ (Student's t-test).

A
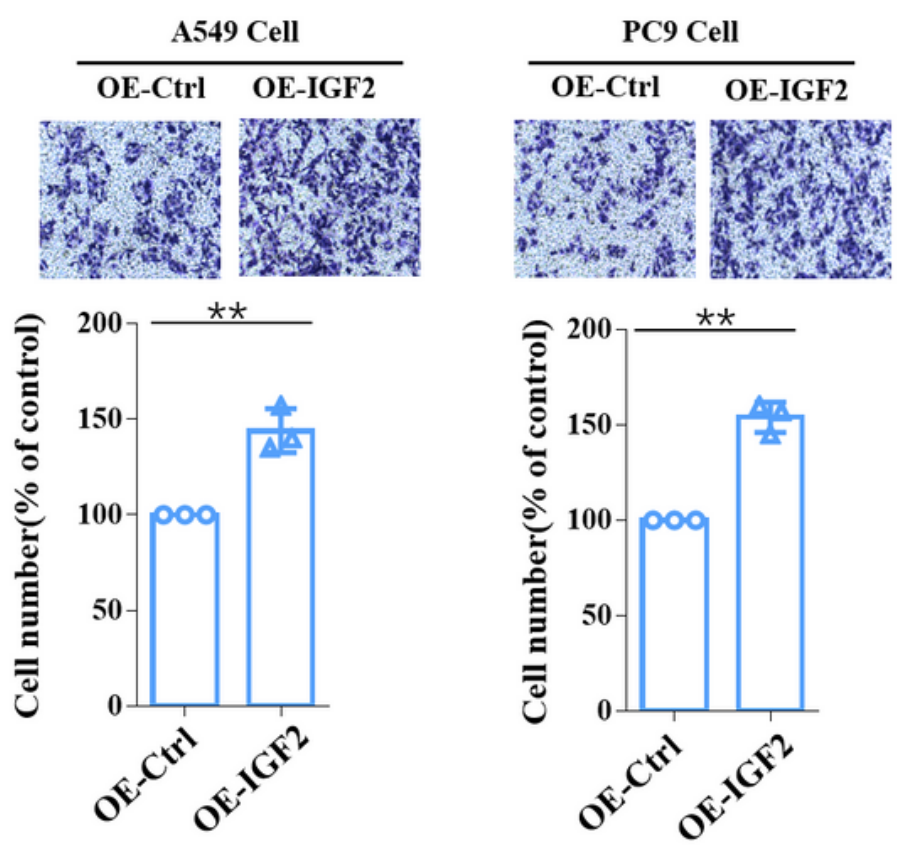

B
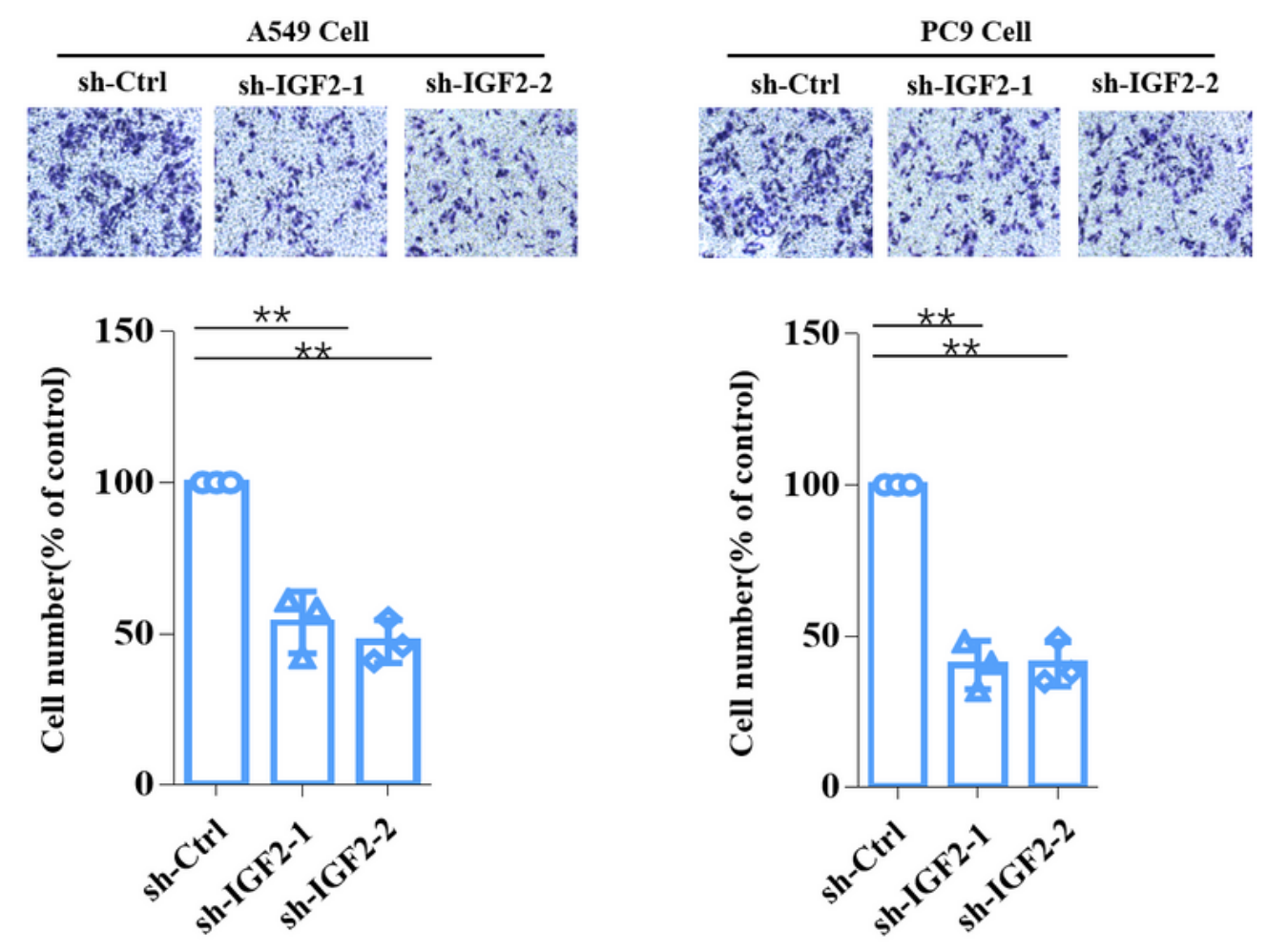

Figure 4 
IGF2 promotes NSCLC cell migration and infiltration. (A) Transwell migration assay of A549 and PC9 cells by overexpression of IGF2. (B) Transwell migration assay of A549 and PC9 cells by inhibits the expression of IGF2. Each bar designates mean \pm s. d. of triplicate experiments. ${ }^{*} \mathrm{P}<0.05$, Student's t-test. $* \star$ : $p<0.01$ (Student's t-test).

A

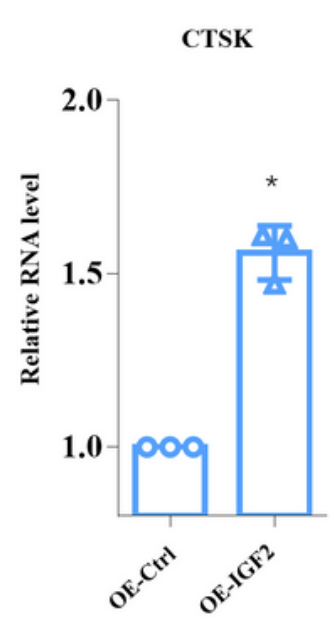

E

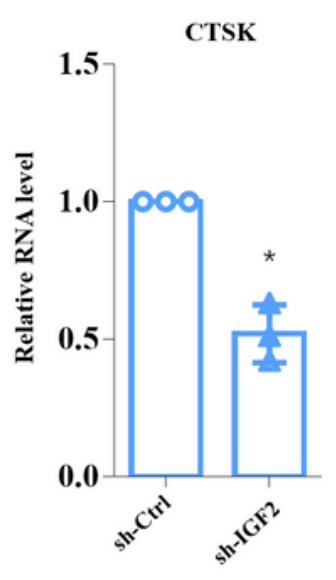

B

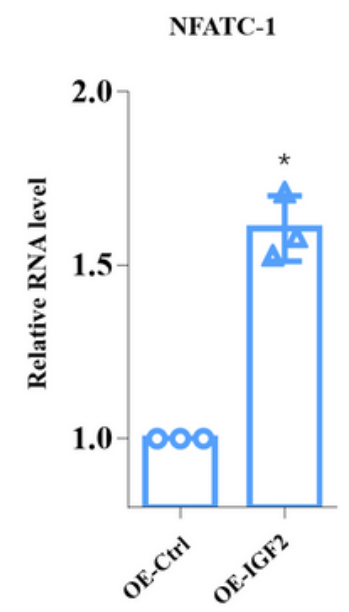

F

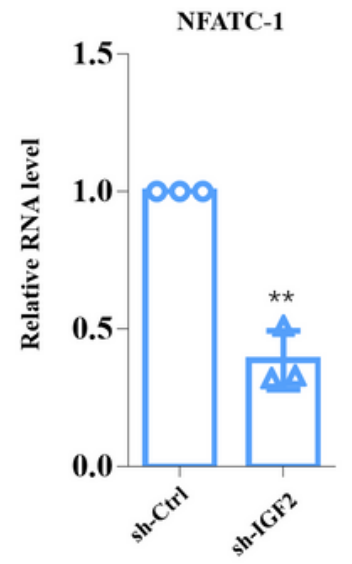

$\mathrm{C}$

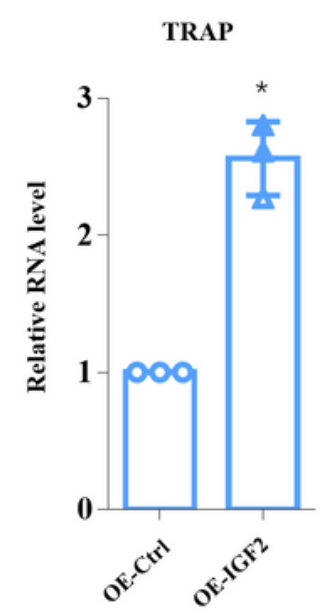

G

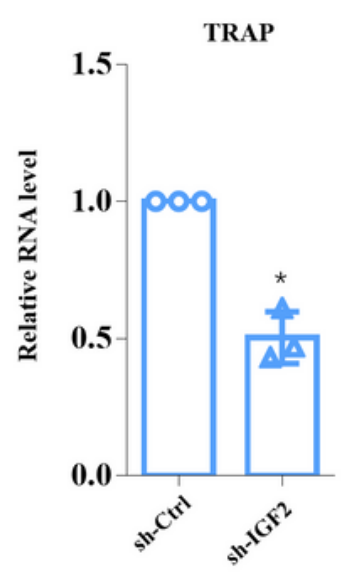

D

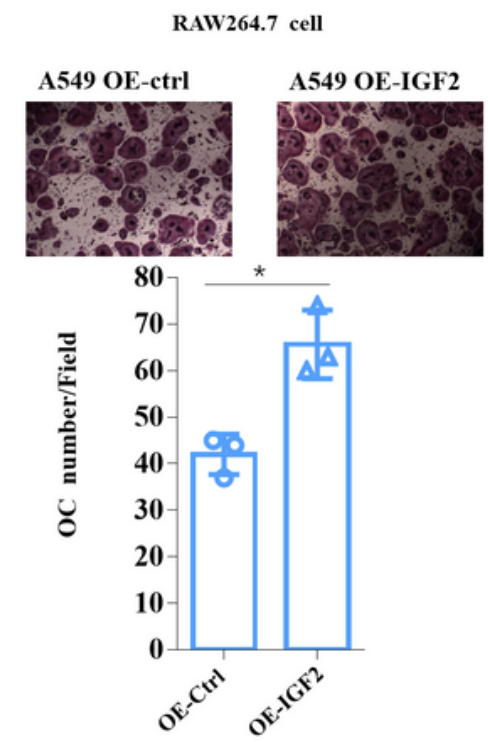

$\mathrm{H}$
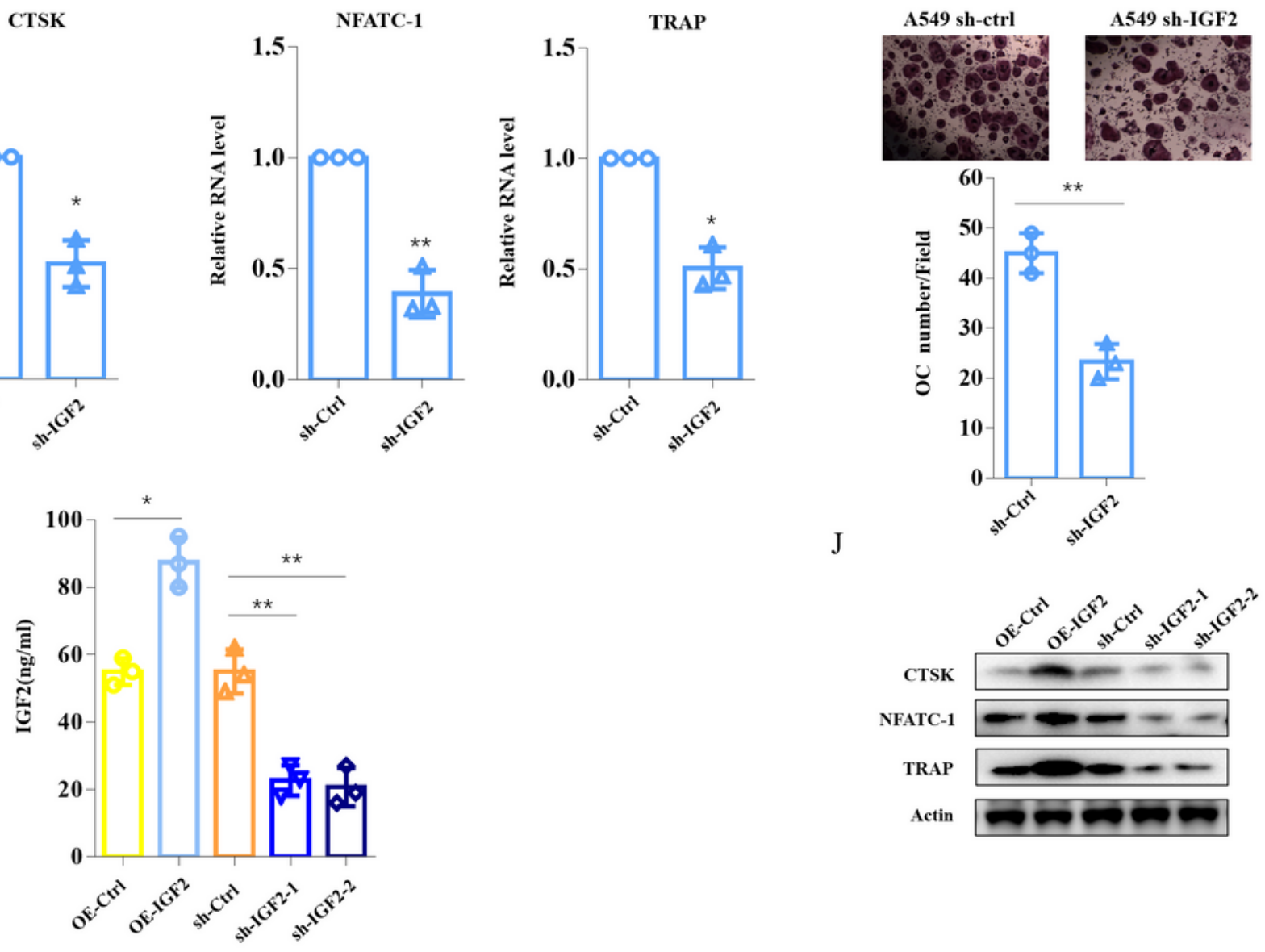

J

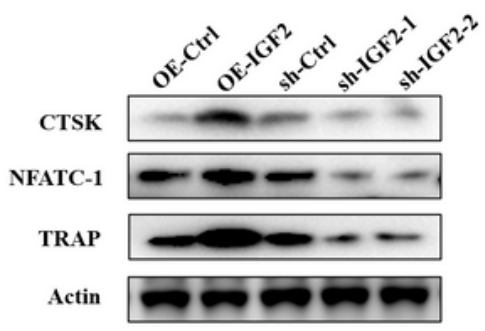

Figure 5 
NSCLC cell promote osteoclast differentiation through secreting IGF2. (A-C) Quantitative RT-PCR assessment of mRNA of CTSK, NFATC-1 and TRAP of Raw264.7 cells after cultured with conditioned medium from A549 sh-ctrl or A549 sh-IGF2 for 7 days. (D) Photomicrograph showing TRAP staining test of Raw264.7 cells after cultured with conditioned medium from A549 sh-ctrl or A549 sh-IGF2 for 7 days. (E-F) Quantitative RT-PCR analysis of mRNA of CTSK, NFATC-1 and TRAP of Raw264.7 cells after cultured with conditioned medium from A549 OE-ctrl or A549 OE-IGF2 for 7 days. (H) Photomicrograph showing TRAP staining test of Raw264.7 cells after cultured with conditioned medium from A549 sh-ctrl or A549 sh-IGF2 for 7 days. (I) The ELISA test showed the expression of IGF2 in conditioned medium of A549 cells after alteration in IGF2 expression. (J) Immunoblot analysis of CTSK, NFATC-1 and TRAP protein expressions after cultured with different conditioned mediums. Each bar designates mean \pm s.d. of triplicate experiments. ${ }^{*} \mathrm{P}<0.05$, Student's t-test. ${ }^{*}: \mathrm{p}<0.01$ (Student's t-test). 
A

RAW264.7 cell

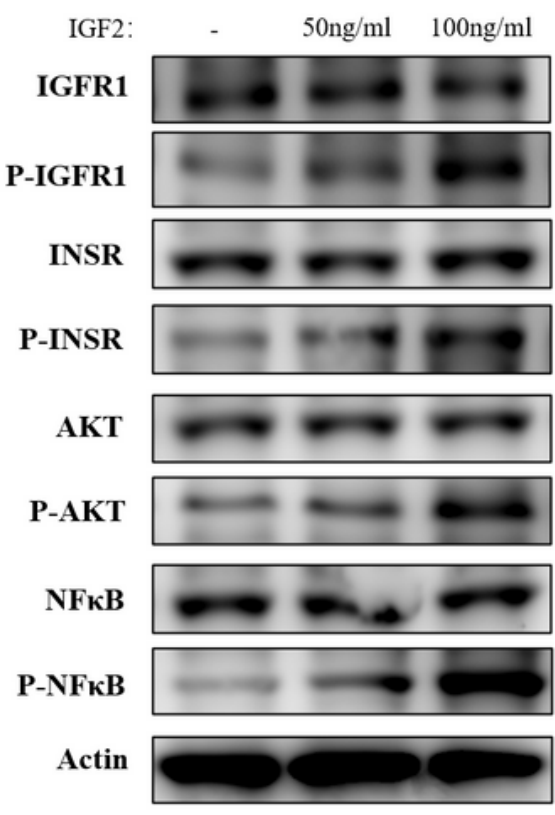

C

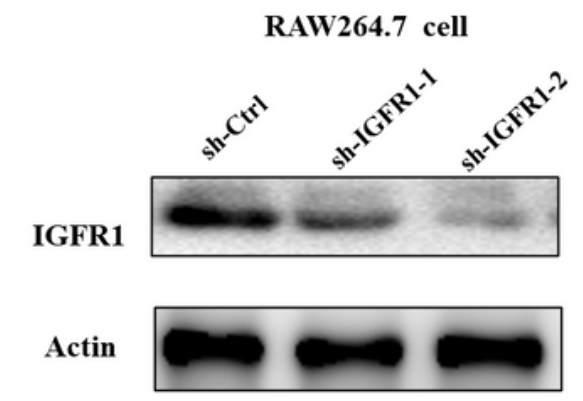

D

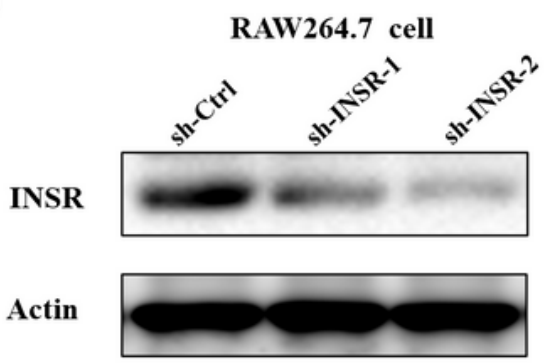

B

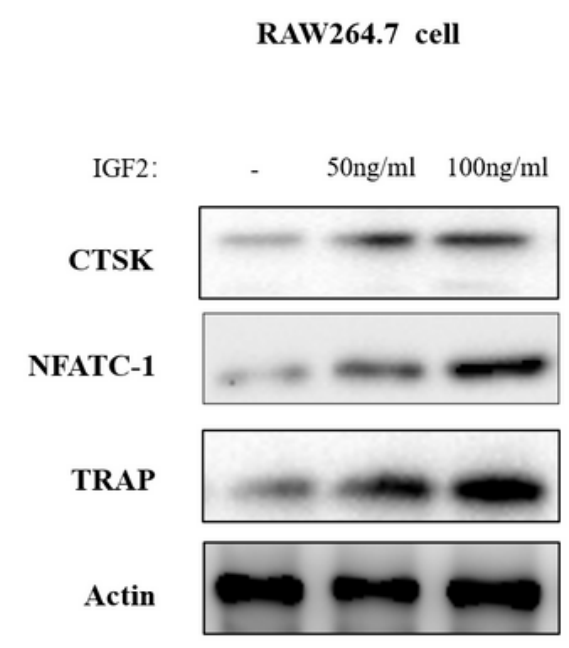

E

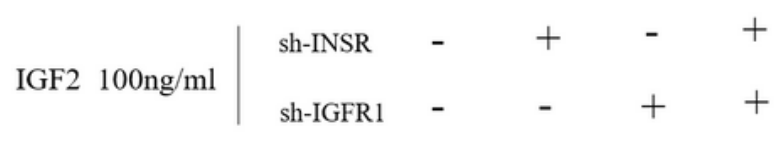
AKT P-AKT
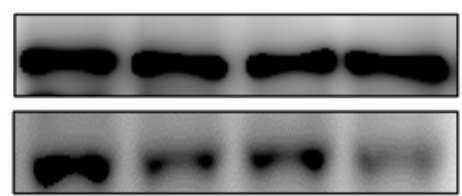

NFкB

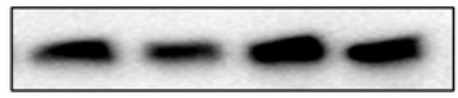

P-NFкB

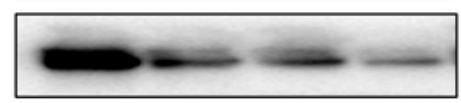

CTSK

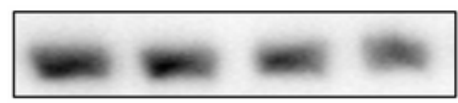

NFATC-1

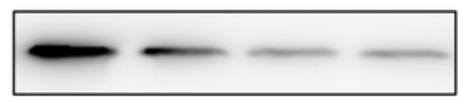

TRAP

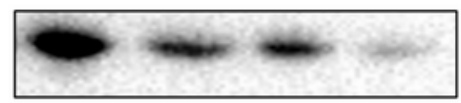

Actin

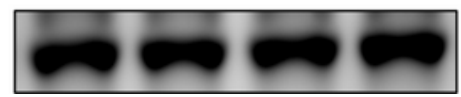

\section{Figure 6}

IGF2 induced osteoclast differentiation in Raw264.7 cells through AKT NFKB pathway by activating IGFR1 and INSR. (A) The Raw264.7 cells were inoculated with IGF2, then the protein contents of IGFR1, PIGFR, INSR,P-INSR, AKT,P-AKT, NFKB and P-NFKB were determined by Western-blotting. (B) Western-blot assays of CTSK, NFATC-1 and TRAP proteins in Raw264.7 cells cultured with different levels of IGF2. (C) The IGFR1 Raw264.7 cell transfects of sh- IGFR1 or sh-CTRL plasmids. (D) The IGFR1 Raw264.7 cell 
transfects of sh- INSR or sh-CTRL plasmids. (E) The IGF2 induced ability of osteoclast differentiation in Raw264.7 cells was blocked by inhibiting IGFR1 and INSR.

\section{Supplementary Files}

This is a list of supplementary files associated with this preprint. Click to download.

- SupplementaryData.xIsx 